\title{
Mucinous cystic neoplasm diagnosed by EUS-guided microforceps biopsy
}

\section{다)(우우}

\author{
Authors \\ Institutions \\ 1 Division of Gastroenterology, Hepatology and Nutrition, \\ Vanderbilt University Medical Center, Nashville, \\ Tennessee, United States \\ 2 Department of Pathology, Microbiology and \\ Immunology, Vanderbilt University Medical Center, \\ Nashville, Tennessee, United States
}

Jordan Orr ${ }^{1}$, Robert Lockwood ${ }^{1}$, Safia Salaria ${ }^{2}$, Anthony Gamboa ${ }^{1}$, Patrick Yachimski ${ }^{1}$

submitted 11.5 .2018

accepted after revision 24.7.2018

Bibliography

DOI https://doi.org/10.1055/a-0743-5477 |

Endoscopy International Open 2018; 06: E1379-E1381

(c) Georg Thieme Verlag KG Stuttgart · New York ISSN 2364-3722

\author{
Corresponding author \\ Jordan Orr, MD, 1660 The Vanderbilt Clinic, Nashville, TN \\ $37232-5280$ \\ Fax: 615-343-7174 \\ jordan.k.orr@vanderbilt.edu
}

\section{ABSTRACT}

Background and study aims Mucinous cystic neoplasms (MCNs) of the pancreas have malignant potential. Current methods for diagnosing MCNs are inadequate. The aim of this case series is to present a novel method for establishing the diagnosis of MCNs. Clinical information from three patients seen at our institution was collected for a case series presentation. Patients were selected retrospectively based on diagnostic results. Three patients were diagnosed with MCNs based on histopathology obtained via microforceps biopsy. Evolving tissue acquisition techniques, such as microforceps intracystic biopsy, have improved the diagnostic yield of endoscopic ultrasound (EUS).

\section{Introduction}

Mucinous cystic neoplasms (MCNs) of the pancreas have malignant potential. Cyst fluid analysis and cytology obtained by endoscopic ultrasound fine-needle aspiration (EUS-FNA) are limited in the ability to distinguish MCNs from alternative types of pancreatic cysts, however, evolving tissue acquisition techniques have improved the diagnostic yield of EUS. We present a series of cases in which the histopathological diagnosis of MCN was established using intracystic microforceps biopsy (MFB).

\section{Case reports}

\section{Patient 1}

A 54-year-old female underwent magnetic resonance imaging (MRI) for evaluation of abdominal pain and was found to have a cystic lesion in the tail of the pancreas. EUS identified a $28 \mathrm{~mm} \times 17 \mathrm{~mm}$ cyst with a mural nodule and thick septations. Transgastric access to the cyst was established using a 19gauge needle and a small-caliber biopsy forceps (Moray Micro
Forceps, US Endoscopy, Mentor, Ohio, United States) was advanced through the needle channel for biopsy of the cyst wall. Histopathology from the forceps biopsy demonstrated fragments of ovarian-like stroma which stained positive for estrogen and progesterone receptors ( $>$ Fig. 1, \ Fig. 2 ), compatible with MCN. The patient was referred for left pancreatectomy.

\section{Patient 2}

A 60-year-old female underwent EUS examination for evaluation of an incidentally detected $25-\mathrm{mm}$ cyst in the body of the pancreas. MFB (Moray Micro Forceps, US Endoscopy, Mentor, Ohio, United States) was performed through a 19-gauge needle ( Fig.3). Histopathology revealed a minute fragment of stroma positive for both estrogen and progesterone receptors with mucinous glands, consistent with MCN. The patient underwent laparoscopic distal pancreatectomy 1 month later with surgical pathology confirming a 25-mm MCN without high-grade dysplasia or malignancy. 


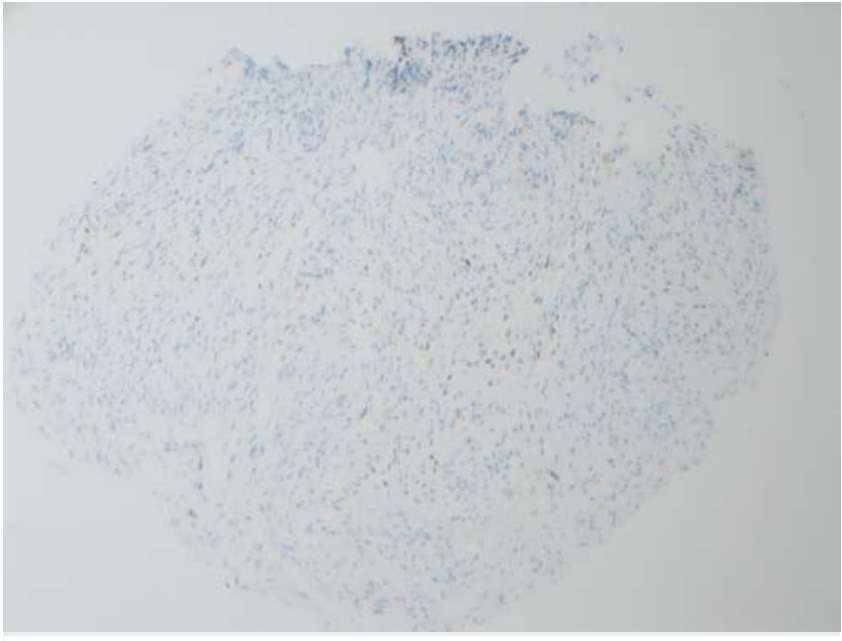

- Fig. 1 Patchy labeling of the ovarian type stroma by an estrogen receptor immunostain. Estrogen receptor immunostain, $20 \times$.

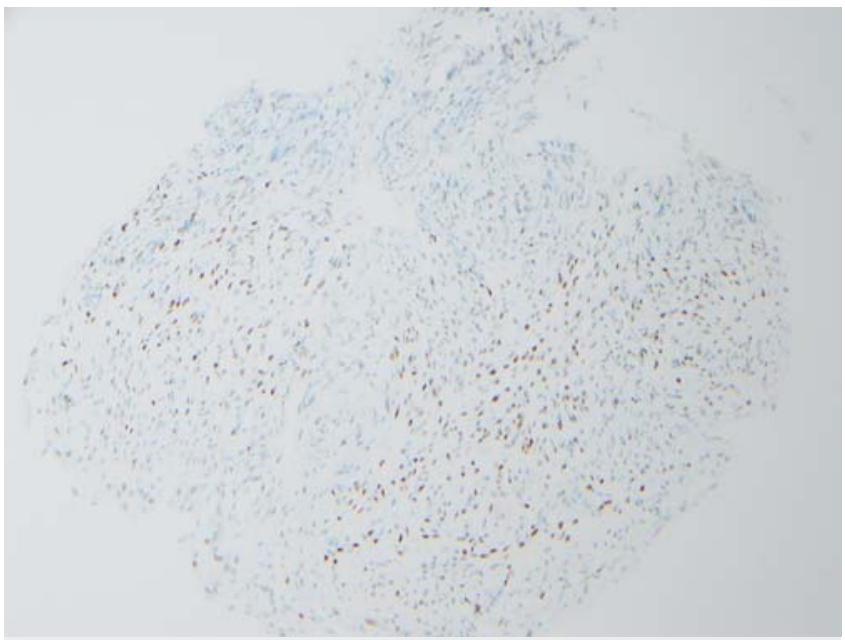

- Fig. 2 A progesterone receptor immunostain highlights the ovarian type stroma within the mesenchyme. Progesterone receptor immunostain, $20 \times$.

\section{Patient 3}

A 55-year-old female underwent EUS for evaluation of a pancreatic cystic lesion with a nonenhancing solid component detected by MRI. EUS evaluation revealed a cystic lesion with thick septations and an associated mural nodule ( Fig.4). Histopathology obtained by MFB (Moray Micro Forceps, US Endoscopy, Mentor, Ohio, United States) revealed a cyst lined by bland cuboidal epithelium without dysplasia, however, spindle cells within the cyst wall expressed nuclear estrogen receptors consistent with a MCN. The patient underwent distal pancreatectomy with splenectomy and surgical pathology confirmed a 15$\mathrm{mm}$ MCN with pancreatic intraepithelial neoplasia, however, no evidence for malignancy.

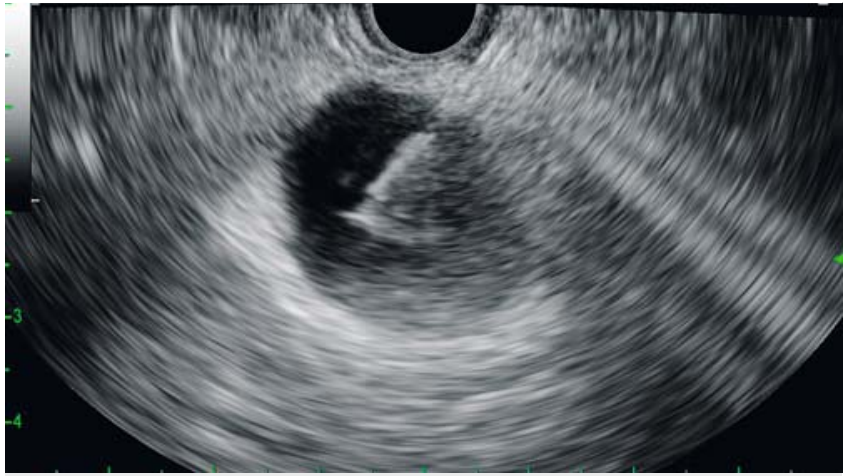

Fig. 3 EUS image of the microforceps being passed into intracystic space.

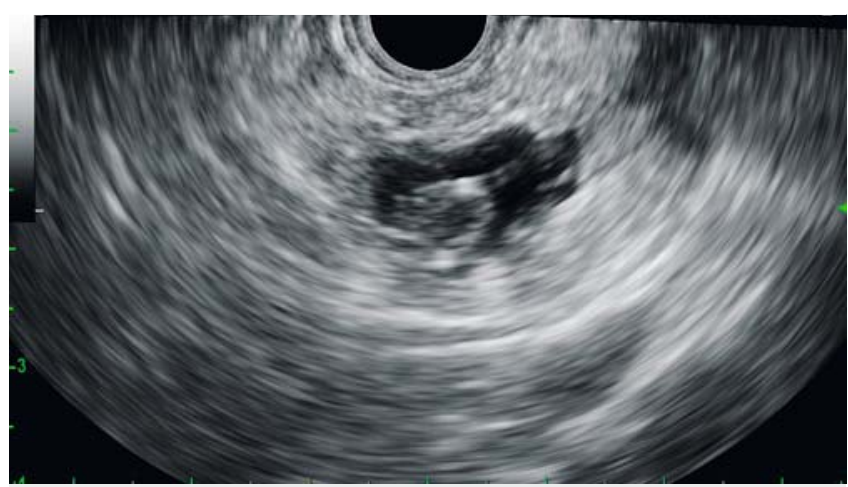

- Fig. 4 EUS image of a MCN with thick septations and mural nodule.

\section{Discussion}

Mucinous cystic neoplasms of the pancreas occur almost exclusively in women, are diagnosed most often in the fifth decade of life, and account for approximately $11 \%$ to $23 \%$ of pancreatic cystic neoplasms [1]. These cysts are typically located in the body or tail of the pancreas (>97\% of cases) and are generally asymptomatic [1]. Given the malignant potential of MCNs, surgical resection is typically recommended. We present a series of cases highlighting the diagnosis of MCNs using MFB. A summary of each case is displayed in > Table 1.

For cases in which the clinical suspicion for MCN is high based on noninvasive imaging, a decision to proceed directly to surgical resection without EUS can be considered. In other instances, EUS may be used to differentiate MCN from other etiologies of pancreatic cysts when the diagnosis is uncertain. Cyst fluid biomarkers and imaging characteristics thus far are inadequate for diagnosis of MCNs and adequate tissue acquisition for histopathological diagnosis of MCNs has remained elusive with traditional modalities.

EUS-guided microforceps biopsy (MFB) is a novel technique that affords intracystic tissue acquisition for histopathological diagnosis of pancreatic cysts, specifically pancreatic cystic neoplasms. Basar et al. evaluated the diagnostic yield of MFB and the ability to provide a specific cyst type diagnosis as compared to traditional cyst fluid cytology analysis. While there was no 


\begin{tabular}{|c|c|c|c|c|c|c|}
\hline & \multirow[t]{2}{*}{ Cyst characteristics } & \multicolumn{4}{|c|}{ FNA Results } & \multirow[t]{2}{*}{ Surgical pathology } \\
\hline & & Amylase & CEA & Cytology & MFB & \\
\hline Case 1 & $\begin{array}{l}28 \mathrm{~mm} \text { x } 17 \text { mm hypoe- } \\
\text { choic cyst; mural nodule; } \\
\text { thick septations }\end{array}$ & - & - & $\begin{array}{l}\text { Non-diagnostic; } \\
\text { negative for ma- } \\
\text { lignancy }\end{array}$ & $\begin{array}{l}\text { Ovarian-like stroma posi- } \\
\text { tive for estrogen/proges- } \\
\text { terone receptors }\end{array}$ & - \\
\hline Case 2 & $\begin{array}{l}\text { 25-mm anechoeic cyst } \\
\text { in pancreatic body; } \\
\text { apparent connection PD }\end{array}$ & $6099 \mathrm{U} / \mathrm{L}$ & $141.8 \mathrm{ng} / \mathrm{mL}$ & $\begin{array}{l}\text { Non-diagnostic; } \\
\text { negative for } \\
\text { malignancy }\end{array}$ & $\begin{array}{l}\text { Spindled fibrous stroma } \\
\text { positive for estrogen/pro- } \\
\text { gesterone receptors }\end{array}$ & $\begin{array}{l}\text { MCN, } 2.5 \mathrm{~cm} \text { in } \\
\text { greatest dimension; } \\
\text { negative for HGD } \\
\text { and malignancy }\end{array}$ \\
\hline Case 3 & $\begin{array}{l}18-\mathrm{mm} \text { cyst in pancreatic } \\
\text { tail; thick septations and } \\
\text { mural nodule }\end{array}$ & - & - & $\begin{array}{l}\text { Non-diagnostic; } \\
\text { negative for } \\
\text { malignancy }\end{array}$ & $\begin{array}{l}\text { Fragments of pancreatic } \\
\text { cyst with ovarian stroma; } \\
\text { spindle cells in cyst wall } \\
\text { express nuclear estrogen } \\
\text { receptors }\end{array}$ & $\begin{array}{l}\text { MCN, } 1.5 \mathrm{~cm} \text { in } \\
\text { greatest dimension; } \\
\text { negative for HGD }\end{array}$ \\
\hline
\end{tabular}

significant difference in the ability to differentiate mucinous from nonmucinous cysts or detect a high risk of malignancy by cytology or MFB, there was considerable difference in the ability to provide a specific cyst type diagnosis (specific cyst type diagnosis for MFB $35.7 \%$ vs cytology $4.8 \%, P=.001$ ) [2]. At this juncture, MFB has proven superior in providing specific cyst diagnosis, however, data supporting its ability to accurately diagnose the degree of dysplasia or carcinoma are lacking. Zhang et al. showed the diagnostic yield of detecting a high-risk cyst, a cyst with a high-grade dysplasia or an adenocarcinoma, is similar between conventional pancreatic fluid analysis and MFB (6.3\% vs $4.2 \%$, respectively; $P=.670$ ).

\section{Conclusion}

This study demonstrated that MFB was far superior in obtaining a specific cyst diagnosis compared to conventional pancreatic fluid analysis ( $50.0 \%$ vs $18.8 \%$, respectively; $P<.001)$, however, findings suggest MFB cannot reliably be used to rule out dysplasia or carcinoma [3]. Large-scale studies will be necessary to fully define the performance characteristics of MFB.

As demonstrated in this case series, EUS-guided MFB of the cyst wall may provide accurate confirmation of diagnosis and enable appropriate patient counseling, risk stratification, and triage for surgical resection.

\section{Competing interests}

None

\section{References}

[1] Basar O, Brugge WR. My treatment approach: pancreatic cysts. Mayo Clin Proc 2017; 92: 1519-1531

[2] Basar O, Yuksel O, Yang DJ et al. Feasibility and safety of microforceps biopsy in the diagnosis of pancreatic cysts. Gastrointest Endosc 2018; 8: 79-86

[3] Zhang ML, Arpin RN, Brugge WR et al. Moray micro forceps biopsy improves the diagnosis of specific pancreatic cysts. Cancer Cytopathol 2018; 126: 414-420 